\title{
Emerging RFID/USN Applications and Challenges
}

\author{
Myo Min Aung \\ School of Air Transport \\ Transportation \& Logistics \\ Aerospace University
}

\author{
Yoon Seok Chang \\ School of Air Transport, \\ Transportation \& Logistics \\ Korea Aerospace University
}

\author{
Jong-Un Won \\ Advanced EMU Research Corps \\ Korea Railroad Research Korea \\ Institute
}

\begin{abstract}
Radio Frequency Identification (RFID) and Wireless Sensor Network (WSN), also known as Ubiquitous Sensor network (USN) are two important wireless sensing technologies that have wide variety of applications and provide unlimited future potentials.

RFID is used to detect presence and location of objects using radio-frequency waves and the ability to do information transfer between tagged objects and readers without line of sight creates tremendous opportunities for linking various objects from real world. These objects are numbered, identified, catalogued, and tracked. WSN is used to sense and monitor the environment through spatially distributed autonomous devices using sensors such as temperature, sound, vibration, pressure and motion etc.

Currently, RFID is emerging as an important technology for revolutionizing a wide range of applications including supply chain management, retail, anti-counterfeiting, baggage handling, and healthcare. Also, WSNs are now used in many civilian application areas, including environment and habitat monitoring, healthcare applications, home automation and traffic control. Initially, RFID and WSN have specific application areas deployed but many applications today also demand for the integration of these two.

There are many emerging applications which adopt these technologies today and they have the potential to unleash new opportunities for growth in the market. We mentioned some of emerging applications which applied RFID or WSNs or both. Lastly, the challenges of these technologies are also discussed.
\end{abstract}

\section{Introduction}

RFID systems and WSNs are emerging as the most ubiquitous computing technologies in history due to their important advantages and their broad applicability. It is expected that in the near future lots of devices such as tags, sensors etc. will grow by multiple orders of magnitude. They gather information about people, animals, objects and its related environment, which means identification, sensing and information processing. According to the reports of IDTechEx research, in 2011, the value of the entire RFID market will be $\$ 5.84$ billion, up from $\$ 5.63$ billion in 2010. This includes tags, readers and software/services for RFID cards, labels, fobs and all other form factors. Also, USN/WSN market is estimated to grow rapidly from $\$ 0.45$ billion in 2011 to $\$ 2$ billion in 2021[1].

WSN and RFID could play an important role in the era of pervasive/ubiquitous computing. The former has a great applicability on monitoring such as environmental and habitat monitoring, while the latter is commonly applied for identifying tasks in such as logistics and industrial production processes. Even though each has good applicability, some applications can be greatly improved by the integration of both technologies.

\section{RFID}

RFID is an automatic identification method, relying on storing and remotely retrieving data using devices called RFID tags or transponders. An RFID tag is an object that can be applied to or incorporated into a product, animal, or person for the purpose of identification using radio waves. The tags can be read by readers from several meters away without line of sight. Most RFID tags contain at least two parts. One is an integrated circuit for storing and processing information, modulating and demodulating a (RF) signal, and other specialized functions. The second is an antenna for receiving and transmitting the signal.

RFID technology has been available for decades but it has only recently risen to prominence. Increasing competitiveness among tag manufacturers has led to significant reductions in the cost of the technology, which in turn means that there are increasing number of industry sectors interested in utilising RFID for applications such as asset tracking and security [2]. Common applications range from highway toll collection, supply chain management, public transportation, controlling building access, animal tracking, developing smart home appliances, 
and remote keyless entry for automobiles to locating children [3].

\section{WSN}

WSN is an emerging network through convergence of micro electro-mechanical systems technology, wireless communications and digital electronics. It is a system which is capable of selfconfiguring, self- networking, self-diagnosing and self-healing. It is considered as a very attractive solution for a wide range of environmental monitoring, distributed surveillance, healthcare and control applications [4].

RFID systems are mainly used to identify objects or to track their location without providing any indication about the physical condition of the object. WSNs on the other hand, are networks of small, costeffective devices that can cooperate to gather and provide information by sensing environmental conditions such as temperature, light, humidity, pressure, vibration, and sound.

\section{RFID and WSN integration}

Nowadays, RFID has been extensively used in many applications; however, RFID has poor ability for some applications to sense environmental information, to process information and to respond to the real world events. WSNs offer a number of advantages over traditional RFID implementations such as multi-hop communication, sensing capabilities and programmable sensor nodes. WSN are made up of many small devices with processing and sensing abilities which should allow us to improve enormously upon the feature set of traditional RFID technology [5].

When sensing capabilities are given to RFID, the line between RFID and sensor network becomes blurred. Many active and semi-active tags have incorporated sensors into their design, allowing them to take sensor readings and transmit them to a reader. They are not quite sensor network nodes because they lack the capacity to communicate with one another through a cooperatively formed ad-hoc network, but they are beyond simple RFID storage tags. This is one of the examples of augmented sensing in the RFID networks [3].

In some applications, only adopting one of the technologies is far enough to meet our needs. For example, in patient health monitoring or in real time business process monitoring which are related to supply or value chain management need identification and contextual information of individual object in real time. RFID is not good enough to collect information about physical world while WSN is not efficient in identification and information management. Although RFID has fairly good sensing capabilities, it is not comparable to
WSN's impressive in-depth sensing capabilities. But the deployment of sensors is expensive. Therefore, based on the RFID, identification of each object can be easily traced with low cost and the information in the RFID tag can be effectively managed with its middleware. On the other hand, based on WSN, the information of each object can be collected in real time and transmitted to sink in an efficient way [5].

At present, the Electronic Product Code (EPC) framework for RFID is focused on the inventory and distribution management. An integrated adaptive sensing infrastructure approach to collect not only identification data but also situational context is essential to achieve visibility and efficiency. Integrated sensing approach could provide to know four Ws : "Who", "What", "When” and "Where”. In particular, RFID enable to give the information on the "Who" (i.e. ID) and WSN can explain the "What" (i.e. an object's state) in detail with it various sensing capabilities. Both technologies can support to know "When" and "Where" (i.e. time and location). An environment adhering to this approach can develop sentient capabilities; becoming responsive and conscious of its state, to ensure that goods are not only in specific locations, but also determine their actual conditions [6].

The integration of RFID systems with sensor networks open new directions. RFID systems are able to accurately identify objects, but often sometimes provide unreliable information concerning the location of an object. Sensors on the other hand, present many advantages in recognizing the location of an object but they are unable to identify it. The efficient integration of RFID and WSNs offers great advantages in accurate location tracking.

Furthermore, their integration allows the condition monitoring of products and the detection of "dangerous" environmental conditions, such as a high temperature or humidity for fragile, sensitive or valuable products. Furthermore, integrated RFID and WSN technologies allow for the automatic condition and tamper detection from a distance without direct and manual inspection in a convenient, inexpensive and less error prone way. There is a great range of possible integration approaches of RFID and WSNs in the supply chain management.

RFID and WSN can be seen as key enablers for smart entities in future of smart environments in which mobile objects and users carrying RFID and WSN will get ubiquitous services according to its identity and real-time sensor information [7].

\section{Emerging Applications}

There are many existing and potential applications of RFID and WSN. Nowadays, RFID has been extensively used in many applications such as manufacturing, transportation and logistics, assets 
tracking and security, healthcare and management etc. The development of WSN was originally motivated by military applications such as battlefield surveillance. However, wireless sensor networks are now using in many civilian and business application areas. There are many emerging applications which will further push the speed of adoption for RFID and WSN technologies. In this paper, we will discuss five areas of emerging applications, among them healthcare and supply chain are examples which need combination of RFID and WSN.

\subsection{Transportation}

RFID applications for transportation mainly function to speed up transactions on the road; the use of RFID in both private and public sectors of transportation is growing. Many public transport organizations today are currently replacing paperbased tickets in plastic public transport cards with RFID chips. These passive and partly rewritable chips are being read on entering a bus, metro, train or ferry. Most cards work as a debit card: money needs to be put on it before travelling, either by putting cash into a machine or a bank transaction. Besides smart transportation cards, mobile telephones with NFC capability can also be used. The advantage of this for passengers is that they do not have to carry a separate smart card [8].

Other uses of RFID in transportation include automatic vehicle registration and identification, car parking and access control, electronic toll collection and fare payments.

\subsection{Identity management}

In the past, various techniques regarding to verification of the identity of an individual in relation to specific actions, transactions, events or other purposes has been in place for long. Also the use of a biometric identification is seen as one of alternatives. It has been used in history already for a very long time. RFID has increasingly pervasive nature of identity management in our modern society. RFID brings the increasingly pervasive nature of identity management in our modern society.

The main application of RFID in identity management is in the e-passport. Identity documents may include national ID cards, ID cards which are used by organisations, drivers license and customer loyalty card etc. RFID-tags used in the cases belong to the group of High Frequency passive tags (13.56 $\mathrm{MHz}$ ). To reduce fraud, easy identity checks, and enhance security, combination of RFID and biometric technologies are used. Therefore, epassports are supposed to contain personal information and some biometric data in digital form. The goal of the e-passport is to provide strong authentication through documents that unmistakably identify their bearers. Protecting e-Passport data against unauthorized access is a crucial part of the security of the entire identification system. The main security and privacy threats to e-passport include clandestine scanning, clandestine tracking, skimming and cloning, eavesdropping, biometric data-leakage and cryptographic weakness [9].

\subsection{Animals tagging}

One of the driving forces of animal tagging is the regulations required for identification and tracking of animals. Within Europe, several regulations are in place to promote animal health by means of a strict system of identification and registration of animals. Animals tagging is getting more and more important due to outbreak of animal diseases such as mad cow disease (BSE), foot and mouse disease (FMD) and bird flu etc.

The opportunities for RFID in animal tracking are identified to be huge, given for instance the outcomes of a forecast which expects in 2015 worldwide some 900 billion food items to be RFID tagged and over 800 million livestock to have more sophisticated, more expensive tags on (or in) them [3]. The tagging of animals (such as pigs, sheep and pets) is now substantial as it becomes a legal requirement in many more territories, with 243 million tags being used for this sector in 2011. This is happening in regions such as China and Australia [1].

Actually, animal tagging connect with traceability for safety of food as human and animals share one health. The integrated system which applies RFID for the identification of individual cattle, and biometric identifiers (e.g. Retinal Scan) for the verification of cattle's identity is used as a solution to the loss of ear tag, the inaccessibility of traceability records and the fraudulent activities occurred in some situations [10].

\subsection{Health care}

The amount of healthcare organisations adopting RFID technology is increasing. RFID technology can greatly improve the performance and responsiveness of healthcare systems. RFID devices can be used to track equipment and people within a medical facility. The use of RFID bracelet for patients can reduce the risk of misidentifying patients and to access patient medical records in a timely manner. The RFID bracelet is a significant RFID-based health care development. It is a plastic band strapped around a patient's wrist with an RFID tag embedded in it. Integration of sensors and RFID in healthcare will improve quality and efficiency of the treatment in various ways. Patient conditions would be monitored continuously and doctors can easily noticed in cases of sudden deterioration of a patient's situation. The 
patient's location can be tracked using RFIDs, while their condition can be monitored using sensors.

Furthermore, medication errors such as outdated treatments orders, inaccurate medical records, and increased costs can be avoided with the use of an integrated RFID-sensor network. Possible applications of integrated RFID and WSNs in the healthcare sector include sensing temperature, measuring blood pressure, heartbeat rate, and $\mathrm{pH}$ value etc. if the emergency situation arises it is necessary to continually monitor, re-evaluate, and diagnose the medical condition of chronic patients. The doctor could easily achieve these data through integrated solution and can do necessary actions. Several RFID-enabled sensors can also form a wireless body area network to ensure that every sensor's signal is being relayed out to the reader. It is worth noting that the power scavenging technique can also be adopted to realize wearable battery-free active RFID-enabled sensors for long term operations. The conceptual diagram of healthcare monitoring system using integrated RFID-sensor network is seen in Figure.1 [3] [11].

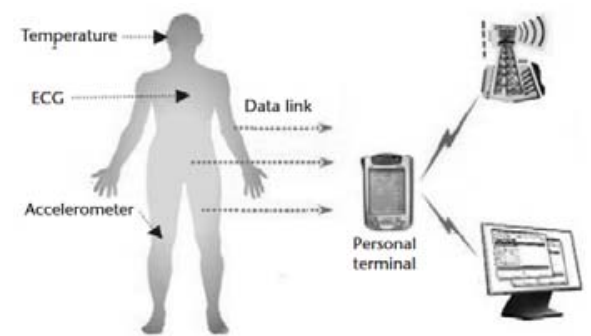

Figure.1 Conceptual diagram of integrated RFIDsensor healthcare monitoring system

There are other several potential applications in healthcare. For eldercare, tagging key objects in a senior's home such as prescription drug bottles, food items, and appliances and embedding small RFID readers in gloves that can be worn by that individual, that person's daily habits can be monitored remotely by a caregiver. This system would develop more accurate record-keeping for medical treatment purposes and could facilitate independent living for senior citizen. RFID in healthcare, although in its infancy, may have great potential to reduce operating costs and improve medical services and patient safety.

\subsection{Supply Chain}

RFID systems have been traditionally used in logistics applications to track and trace the location of products throughout different points in the supply chain. RFID tags attached to products are capable of providing real-time tracking information across the supply chain. Intelligent asset tracking is one of the examples how integrated solution could benefit the logistics operations. IDTechEX, a technology research firm, estimates RFID business to jump from about \$5 billion in 2007 to over \$25 billion in 2017. All of this makes RFID as one of the single biggest drivers of technology spending in supply chain management [12].

In an enterprise environment, sensor technologies combined with ID technologies would significantly improve the enterprise resource visibility and, thus, improve the enterprise operational efficiency. This combination could bring more value to enterprise applications. For example, during the food transportation, it is important that the temperature of the food be monitored and controlled. A better decision with the related enterprise operations could then be made based on information of not only the location of an asset, but also its condition [13]. Moreover, sensors and RFID integration system has been used in the phases of product lifecycle management.

In Table.1, we compare features of some applications which based on either RFID or WSN technology alone or integrated solution.

\section{प. Challenges}

RFID technology has the apparent advantages over traditional bar code system. Contactless, $\mathrm{read} /$ writable data, no line of sight, variety of read ranges, wide data-capacity range, multiple tags read and accuracy are some of the benefits using RFID other than bar code. But still there are issues to solve in the area of performance, environmental factors' impact, tags read limitation, hardware interference, standardization and cost etc [6].

RFID is found as the most cutting edge technology for supply chain integrity and traceability. But the problem is still the high cost of tags used in these systems, even though the prices have decreased significantly in recent years [14]. Competing standards have been one of the more difficult issues for RFID, and as a result, most RFID applications have been closed systems. Moreover, readability of RFID tags through metal, glass and liquid is difficult to achieve $100 \%$.

There have been severe concerns on the risks that RFID poses to the end-users privacy. Privacy in case of healthcare is certainly an important issue to be considered. In case of using RFID, privacy is mainly related to frequency transmission and to unauthorized access to people data stored in databases. Keeping access to a secure database is required to prevent unauthorized users to accessing personal data [3]. 
Table.1. Comparison for RFID, WSN and RFID+WSN based applications

\begin{tabular}{|c|c|c|c|}
\hline $\begin{array}{l}\text { Application } \\
\text { Areas } \\
\end{array}$ & RFID Based Application & WSN Based Application & $\begin{array}{l}\text { RFID+WSN-Based } \\
\text { Application }\end{array}$ \\
\hline Asset Tracking & $\begin{array}{l}\text { Can track fixed and mobile } \\
\text { assets. Can retrieve assets' id, } \\
\text { location and time. Improve } \\
\text { asset utilization, Optimize } \\
\text { asset visibility and } \\
\text { availability. }\end{array}$ & $\begin{array}{l}\text { Can extend range using } \\
\text { multihop network. Know } \\
\text { assets' conditions through } \\
\text { sensors (temperature, } \\
\text { humidity, GPS, motion, } \\
\text { pressure etc. ) but cannot say } \\
\text { specific details about assets }\end{array}$ & $\begin{array}{l}\text { Available not only RFID data but } \\
\text { also additional sensing data so } \\
\text { more visible to the assets. Wide } \\
\text { sensing range coverage. Useful } \\
\text { for product life cycle } \\
\text { management. }\end{array}$ \\
\hline Cold Chain & $\begin{array}{l}\text { Can track perishable foods } \\
\text { and pharmaceutical products. } \\
\text { Know the source of origin, } \\
\text { expired dates and } \\
\text { specifications etc. but have } \\
\text { poor knowledge about the } \\
\text { condition of the products } \\
\text { moving throughout the cold } \\
\text { supply chain }\end{array}$ & $\begin{array}{l}\text { Visibility over products } \\
\text { condition in the cold chain } \\
\text { using sensors (humidity, } \\
\text { temperature and gas etc.). } \\
\text { Can give alarm or send } \\
\text { message for proactive } \\
\text { measures. But poor capability } \\
\text { to collect huge identification } \\
\text { data. }\end{array}$ & $\begin{array}{l}\text { While RFID keep products } \\
\text { information, WSN can do } \\
\text { sensing, monitoring and control } \\
\text { tasks. More knowledgeable and } \\
\text { intelligent than using single } \\
\text { technology and can help to make } \\
\text { supply chain decisions. Can help } \\
\text { to make corrective actions. }\end{array}$ \\
\hline $\begin{array}{c}\text { Machine } \\
\text { Condition } \\
\text { Monitoring }\end{array}$ & $\begin{array}{l}\text { Embed tags with machines } \\
\text { and parts for tracking. But } \\
\text { cannot understand machines } \\
\text { state. Need careful placement } \\
\text { for readers. Can keep } \\
\text { machines details infomation }\end{array}$ & $\begin{array}{l}\text { Collect real time data from } \\
\text { industrial sensors (e.g. } \\
\text { temperature, vibration, } \\
\text { pressure, motion and photo } \\
\text { etc.) for health and operation } \\
\text { of machines. Proactive, } \\
\text { predictive and preventive } \\
\text { maintenance can be achieved }\end{array}$ & $\begin{array}{l}\text { Real time check for machine } \\
\text { health conditions via industrial } \\
\text { sensors. Easy to track faulty } \\
\text { machine. Achieve proactive, } \\
\text { predictive and preventive } \\
\text { maintenance so less machine } \\
\text { downtime and improve } \\
\text { productivity. Fault tolerance and } \\
\text { reliable system can be achieved. }\end{array}$ \\
\hline Healthcare & $\begin{array}{l}\text { Tags attached with patients, } \\
\text { old aged people and medical } \\
\text { equipments and products. } \\
\text { Can prevent drugs } \\
\text { counterfeiting }\end{array}$ & $\begin{array}{l}\text { Monitor the environmental } \\
\text { condition of storage, } \\
\text { transport and distribution of } \\
\text { medical equipments, vaccines } \\
\text { etc. }\end{array}$ & $\begin{array}{l}\text { Wearable sensors can assist to } \\
\text { know the vital body functions in } \\
\text { real time. Easy to track patient } \\
\text { history by using ID at the same } \\
\text { time. }\end{array}$ \\
\hline $\begin{array}{l}\text { Security and } \\
\text { Access Control }\end{array}$ & $\begin{array}{l}\text { Can check security based } \\
\text { only on id related data. It } \\
\text { fails if we need to check } \\
\text { more information other than } \\
\text { ID. }\end{array}$ & $\begin{array}{l}\text { Many sensors (image, } \\
\text { ultrasonic and motion etc. ) } \\
\text { information applicable for } \\
\text { security other than ID. But } \\
\text { lack of specific information } \\
\text { about individual items and } \\
\text { people etc. }\end{array}$ & $\begin{array}{l}\text { Ensure security and safety of } \\
\text { environment. } \\
\text { authentication. Strengthen } \\
\text { surveillance network and gain } \\
\text { more visibility }\end{array}$ \\
\hline
\end{tabular}

Therefore, database security is a critical aspect of any analysis of privacy concerns associated with RFID use, because the tags themselves may contain only limited data, such as a number in the case of EPC chips. The information associated with that number will be stored on a server of the product manufacturer or other authorized user, where it can be linked to additional data.

While RFID provides promising benefits such as inventory visibility and business process automation, some significant challenges on information systems and technologies (IS/IT) need to be overcome before these benefits can be realized. One important issue is how to process

like signal processing, hardware design, supplychain logistics, privacy rights, and cryptography. and manage RFID data, which is typically in large volume, noisy and unreliable, timedependent, dynamically changing, and of varying ownership.

Another issue is how to seamlessly integrate lowlevel RFID data into (existing) enterprise information infrastructures (e.g., upper-level business processes). Finally, given the ability of inexpensively tagging and thus monitoring a large number of items and/or people, RFID raises some serious security and privacy concerns. RFID tags are also vulnerable to counterfeiting and theft. Indeed, RFID privacy and security are still challenging research areas that involve with many disciplines,

Integration of RFID and WSNs raises new challenges from the interference stand-point. There 
will have a lot of work to be done on how to reduce the interference in large RFID networks and WSNs since large number of devices adversely increase the potential for interference. For WSN, a node's battery is not replaceable in real time scenarios, so its energy is the most important system resource. An RFID system where data is collected at one or several centralized points is typically not energy-efficient. Therefore, energy efficiency will be a crucial problem when combining RFID and WSN and a good scheme to conserve energy is needed [15].

\section{Conclusion}

We have presented RFID and WSN, the two pillars of ubiquitous computing and their emerging applications. The need of their integration for some application areas is highlighted. The industry expectation for these two technologies is very high but there are some challenges still left to solve, however, in the near future, we will see many ubiquitous applications not only in industry but also in our society.

\section{References}

[1] IDTechEx (2011), RFID reports http://www.idtechex.com/research/?catflag=R $\quad$ (25 Oct 2011)!

[2] Mason, A., Shaw, A., Al-Shamma’a, A.I., and Welsby. T. (2006), RFID and Wireless Sensor Network Integration for Intelligent Asset Tracking Systems, In Proceedings of GERI Annual Research Symposium (GARS), Liverpool, UK.

[3] Mitrokotsa, A. and Douligeris, C. (2010),” Integrated RFID and Sensor Networks: Architectures and Applications”, in RFID and Sensor Networks, CRC press, p. 511-530.

[4] Akyildiz, I. F., Su, W., Sankarasubramaniam, Y., and Cayirci, E. (2002), “A Survey on Sensor Networks”, IEEE Communications Magazine, Vol. 40, No.8.

[5] Li, Z., Shen, H., and Alsaify, B. (2008), Integrating RFID with Wireless Sensor Networks for Inhabitant, Environment and Health Monitoring, In Proceedings of IEEE International Conference on Parallel and Distributed Systems, Melbourne, Australia , pp. 639-646.

[6] Pradhan, S. et al., (2005), "RFID and Sensing in the Supply Chain: Challenges and Opportunities", HP technical report, HP Development Company, L.P.

[7] Lopez, T. S., Kim, D. Y., and Park , T. S. (2006) “A Service Framework for Mobile Ubiquitous Sensor Networks and RFID”, In Proceedings of International Symposium on Wireless Pervasive Computing, Bangkok, Thailand.

[8] European Parliament (2007), RFID and Identity Management in Everyday Life, STOA project RFID \& Identity Management.

[9] European Comission (2007), RFID Technologies: Emerging Issues, Challenges and Ploicy Options, JRC Scientific and Technical Reports, EUR 22770 EN.
[10] Shanahan, C., Kernan, B., Ayalew, G., McDonnell, K., Butler, F., \& Ward, S. (2009). A framework for beef traceability from farm to slaughter using global standards: An Irish perspective. Computers and Electronics in Agriculture, 66(1), 62-69.

[11] Rida, A., Yang, L., and Tentzeris, M. (2010), RFIDEnabled Sensor Design and Applications, Artech House., Boston, London.

[12] IDTechEx (2007), RFID Forecasts, Players and Opportunities 2007 to 2017, Research Report.

[13] Roussos, G. (2008), Network RFID: Systems, Software and Services, Springer, Verlag-London.

[14] Aarnisalo, K., Heiskanen, S., Jaakkola, K., Landor, E., \& Raaska, L. (2007). Traceability of foods and foodborne hazards. VTT Technical Research Centre of Finland Research Notes 2396.

[15] Zhang, L. and Wang, Z.(2006), Integration of RFID into Wireless Sensor Networks: Architectures, Opportunities and Challenging Problems, In Proceedings of 5th Int'l Conf: on Grid and Cooperative Computing Workshop, Changsha, China.

\section{Acknowledgements}

This work was supported in part by Korea Research Foundation under Grant KRF-2006-211-00304 and Smart Cold Chain Management Project SCCM 2008-215:56-3 of Ministry of Knowledge Economy,. The Authors would like to acknowledge this support. 